\title{
Detection of parts in patterns and images
}

\author{
STEPHEN K. REED and JEFFREY A. JOHNSEN \\ Case Western Reserve University, Cleveland, Ohio 44106
}

\begin{abstract}
Subjects performed in an embedded-figures detection task which required them to judge whether one pattern was a part of another. In the perception condition, the part was presented before the complete pattern, but in the imagery condition, the part was presented after the complete pattern. Subjects made fast, but inaccurate, responses in the perception task when RT s were recorded, but the error rate declined substantially when they were given 10 sec to make a decision. In the latter condition, subjects failed to detect a part on $14 \%$ of the trials in the perception condition and on $72 \%$ of the trials in the imagery condition when a correction was made for prior perception of the part. A subsequent experiment showed that the high error rate in the imagery task was not the result of the subject's inability to remember the complete pattern. The complexity of mental operations and the limited accuracy of visual images are considered as possible alternative explanations of the results.
\end{abstract}

One theory of pattern recognition proposes that subjects store patterns in memory in the form of structural descriptions. The term structural description is used here to refer to the way in which subjects segment a pattern to describe how the features or parts of a pattern interrelate (see Sutherland, 1968, or Reed, 1973, 1974 for a more detailed discussion). A description of the letter A might be "the top of a negative oblique line is joined to the top of a positive oblique line, with their midpoints connected by a horizontal line." Such a description could be stored in memory as a verbal description or as a visual image in which the relationships among the parts are preserved in a mental picture. Most current models of human memory emphasize the existence of both verbal and visual codes, leaving the experimenter with the problem of how to eliminate the verbal code in order to study visual imagery in its "pure" form.

One obstacle in the study of visual imagery is the role that language may have in facilitating performance on a task which is supposed to measure the accuracy of visual imagery. If asked to draw the Star of David, my memory for the pattern would likely be influenced by possession of such verbal concepts as "triangle," "inverted," and "join." If asked whether the Star of David contains a parallelogram, my response would be less likely influenced by language if I had not previously noticed that a parallelogram is part of the Star of David. Asking subjects about the possible parts of a pattern can therefore provide experimenters with a technique for assessing the accuracy of visual imagery, since parts which have not been previously seen could not activate verbal concepts associated with them.

\footnotetext{
This research was supported by NIMH Grant MH-21115 to the first author. We would like to thank Dr. Jean Mandler, whose comments on an earlier paper motivated this research. Requests for reprints should be sent to Stephen K. Reed, Department of Psychology, Case Western Reserve University, Cleveland, Ohio 44106.
}

In a previous paper, Reed (1974) reported the results of two experiments which required subjects to indicate whether the second of two sequentially presented patterns was a part of the first pattern. The large number of errors found using this paradigm was interpreted by the author as being consistent with the view that subjects encode a pattern as a structural description and find it difficult to recognize a part of the pattern which does not match their structural description. Reed also interpreted the results as supporting the hypothesis that visual images lack detail when not supported by verbal concepts. He argued that if subjects had accurate and detailed visual images, they should be able to scan the visual image for the presence of a part even though they did not originally perceive the part and thereby activate verbal concepts which could name or describe it.

The preceding arguments were based on two major assumptions. First, it was assumed that finding the part would not be a difficult task if the pattern were physically present. In other words, poor performance was not the result of the difficulty of the embedded figires task per se, but was the result of having to scan a visual image rather than a perceptual pattern. Second, it was assumed that subjects could remember and recognize the first pattern even though they could not recognize some of its parts. Although a structural description could provide an adequate memory code for the complete pattern, it would not necessarily be adequate for recognizing isolated parts of the pattem which did not match the subject's description. If a person remembers the Star of David as two overlapping triangles, he should be able to recognize the Star of David, but not necessarily a parallelogram as a part of the Star of David.

The objective of the following three experiments was to examine these assumptions. The first experiment tested the subjects' ability to detect a possible part in a perceptual pattern. The experiment replicated 
Experiment I of Reed (1974) but reversed the order of the two patterns composing each pair. Subjects were instructed to indicate whether the first pattern was a part of the second pattern and could therefore scan a pattern which was physically present. It should be noted that this experiment is very similar to the embedded figures task designed by Gottschaldt (1926) to study the effect of experience on perceptual organization. Gottschaldt found that subjects rarely reported parts embedded in a pattern which did not correspond to their perceptual organization of the pattern. This was true even when they were shown the isolated parts many times before seeing the patterns containing them. Although these findings suggest that subjects may have difficulty in detecting a part in a perceptual pattern, Gottschaldt also discovered that subjects could find the part if they were given sufficient time and and could simultaneously view the part and pattern containing it.

The second experiment directly compares the subjects' ability to scan a visual image as opposed to a perceptual pattern. Subjects in the imagery condition were shown the complete pattern before the part. All subjects were given $10 \mathrm{sec}$ to make their decision in
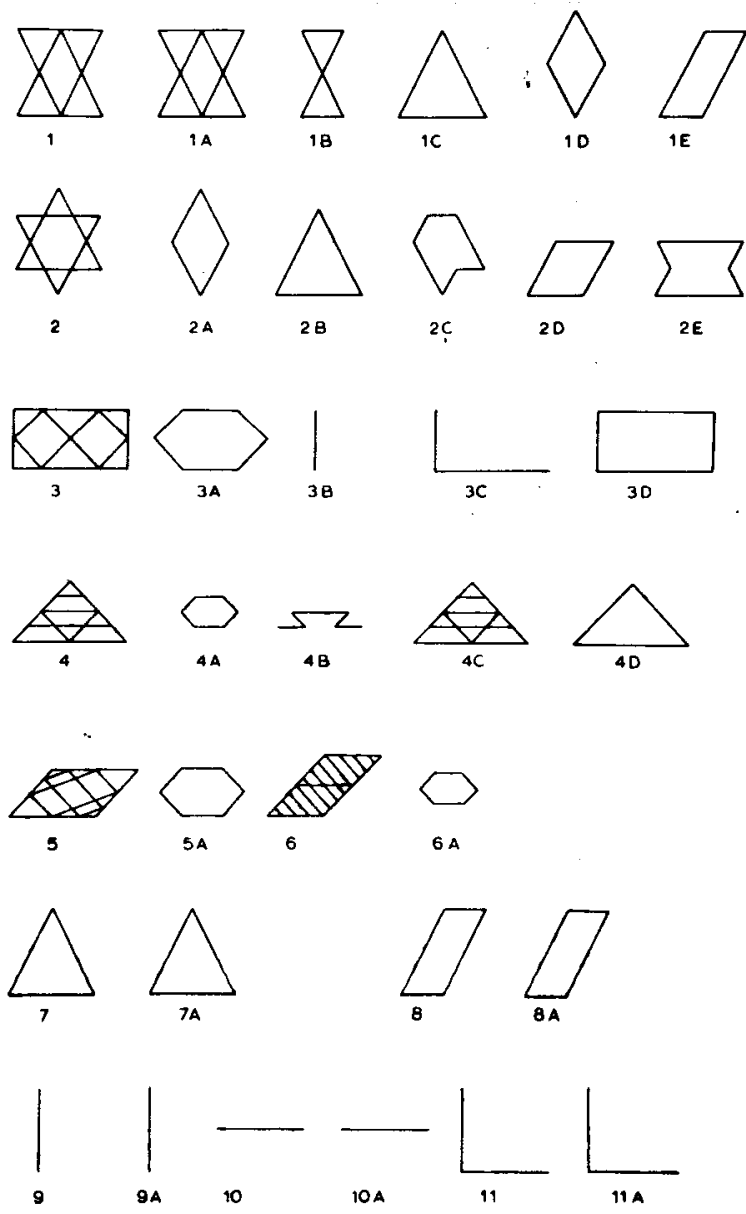

Fig.1. Positive pairs of patterns used in Experiment I (From Reed, 1974). order to improve their accuracy by eliminating RT as a performance measure. The third experiment used the imagery paradigm and examined subjects' memory for the complete pattern. After being tested on possible parts of a pattern, the subjects were asked to draw the pattern.

\section{EXPERIMENT I}

\section{Method}

Subjects and Procedure. The subjects were 32 undergraduates enrolled in an introductory psychology course at Case Westem Reserve University. They received course credit for their participation.

The experiment was designed to replicate Experiment I of Reed (1974), except for reversing the order of the two patterns composing each pair. The task was to decide whether the first pattern was a part of the second pattern. Each trial consisted of the presentation of the first pattern for $1 \mathrm{sec}$, a 1.5 -sec retention interval, and the presentation of a second pattern. Subjects responded positively by pressing a switch held in their right hand and negatively by pressing a switch held in their left hand. The second pattern remained on the screen until the subject responded. Reaction times were recorded to the nearest hundredth of a second by a Lafayette stop clock. A warning tone occurred $0.5 \mathrm{sec}$ before the presentation of the second
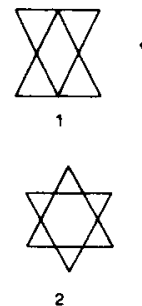

2
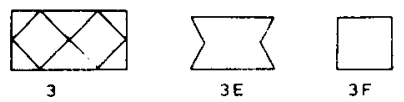
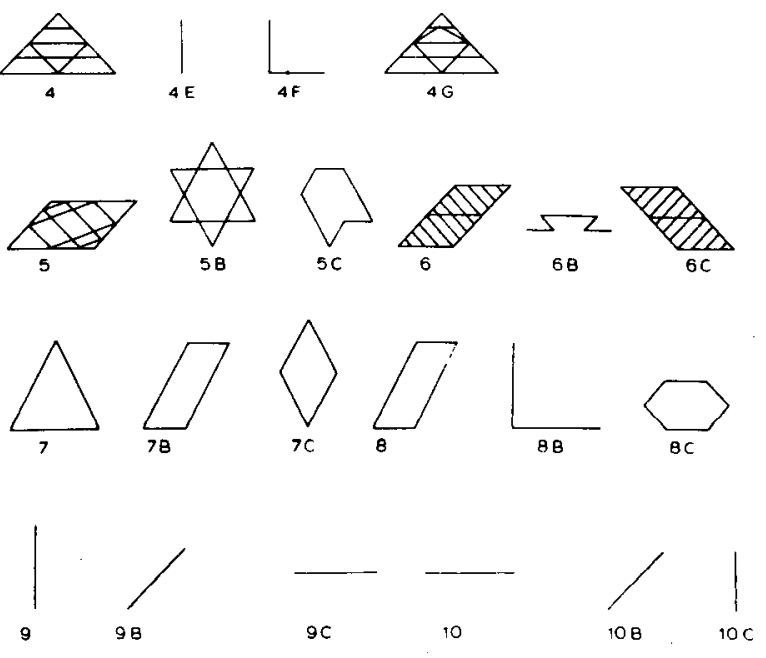

Fig. 2. Negative pairs of patterns used in Experiment I (From Reed, 1974). 
Table 1

Reaction Times for Positive Pairs in a Perception Task

\begin{tabular}{crrrrrr}
\hline Pattern & $\begin{array}{r}\text { Cor- } \\
\text { rect }\end{array}$ & RT & SD & $\begin{array}{c}\text { Incor- } \\
\text { rect }\end{array}$ & RT & SD \\
\hline 1A & 31 & 1.01 & .36 & 1 & 1.42 & \\
1B & 27 & 1.41 & .51 & 5 & 1.41 & .71 \\
1C & 26 & 1.49 & .60 & 6 & 1.75 & .56 \\
1D & 29 & 1.00 & .32 & 3 & 1.33 & .44 \\
1E & 22 & 1.51 & .55 & 10 & 1.42 & .40 \\
2A & 10 & 1.82 & 1.21 & 22 & 1.75 & .76 \\
2B & 30 & 1.11 & .37 & 2 & 1.03 & .27 \\
2C & 12 & 2.28 & 1.52 & 20 & 2.10 & 1.15 \\
2D & 16 & 2.22 & 1.36 & 16 & 1.63 & .62 \\
2E & 25 & 1.41 & .59 & 7 & 1.08 & .35 \\
3A & 11 & 2.03 & .91 & 21 & 1.54 & .78 \\
3B & 29 & 1.24 & .47 & 3 & 1.93 & .84 \\
3C & 28 & .99 & .33 & 4 & .90 & .16 \\
3D & 32 & 1.00 & .39 & 0 & & \\
4A & 4 & 2.12 & 1.05 & 26 & 1.88 & .91 \\
4B & 25 & 2.13 & 1.17 & 7 & 2.44 & 1.01 \\
4C & 32 & 1.01 & .46 & 0 & & \\
4D & 31 & .97 & .42 & 1 & 1.91 & \\
5A & 8 & 2.52 & 1.14 & 24 & 2.18 & 1.10 \\
$6 \mathrm{~A}$ & 4 & 1.60 & 1.02 & 28 & 1.64 & .89 \\
$7 \mathrm{~A}$ & 29 & .96 & .42 & 3 & 1.16 & .25 \\
$8 \mathrm{~A}$ & 31 & .86 & .41 & 1 & 1.08 & \\
$9 \mathrm{~A}$ & 31 & .75 & .22 & 1 & 2.23 & \\
$10 \mathrm{~A}$ & 31 & .83 & .41 & 1 & 3.70 & \\
11A & 31 & .85 & .31 & 1 & .96 & \\
\hline & & & & & &
\end{tabular}

pattern, and a Gerbrands tachistoscopic shutter provided a rapid onset and termination of the slides. A Kodak Carousel projector was used to rear-project the stumuli onto a translucent screen, producing a pattern which subtended a visual angle of $6 \mathrm{deg}$.

The experiment consisted of 10 practice trials, followed by 50 experimental trials. The first pattern was a part of the second pattern on $50 \%$ of the trials. Figure 1 shows the 25 positive pairs, and Figure 2 shows the 25 negative pairs. Patterns were presented in a random order under the constraint that at least two trials intervened between a repetition of the same second pattern and that runs of positive pairs or runs of negative pairs could not be greater than four in length. There were four different presentation orders used throughout the experiment.

\section{Results}

Table 1 shows the number of correct responses, the number of incorrect responses, the mean reaction times, and the standard deviation for the 25 positive pairs. Table 2 shows the corresponding data for the 25 negative pairs. The magnitude of the RTs was similar to those obtained previously in the imagery task (Reed, 1974). The mean correct response time for the 25 positive pairs was $1.58 \mathrm{sec}$ in the perception task and $1.64 \mathrm{sec}$ in the imagery task. The Pearson product-moment correlation between mean response times for the 25 positive stimuli in the two tasks was significant $[\mathrm{r}(23)=.64, \mathrm{p}<.011$. but not exceptio- ally high.

The most striking aspect of the data shown in Table 1 is the large number of errors for some of the stimulus pairs. For example, responses to Pairs 2A, 2C, 3A, 4A, $5 \mathrm{~A}$, and $6 \mathrm{~A}$ were more often incorrect than correct. The
Table 2

Reaction Times for Negative Pairs in a Perception Task

\begin{tabular}{|c|c|c|c|c|c|c|}
\hline Pattern & $\begin{array}{l}\text { Cor- } \\
\text { recr }\end{array}$ & $\mathrm{RT}$ & $S D$ & $\begin{array}{l}\text { Incor- } \\
\text { rect }\end{array}$ & RT & SD \\
\hline $1 \mathrm{~F}$ & 30 & 1.31 & .66 & 1 & 1.99 & \\
\hline $1 G$ & 29 & 1.80 & .83 & 1 & 1.56 & \\
\hline $1 \mathrm{H}$ & 31 & 1.30 & .49 & 1 & .36 & \\
\hline 11 & 31 & 1.65 & .69 & 1 & 2.00 & \\
\hline $2 \mathrm{~F}$ & 25 & 1.74 & 1.06 & 5 & 1.53 & .99 \\
\hline $2 \mathrm{G}$ & 32 & 1.33 & .57 & 0 & & \\
\hline $2 \mathrm{H}$ & 30 & 1.23 & .45 & 2 & 1.10 & .20 \\
\hline $2 \mathrm{I}$ & 32 & 1.61 & .78 & 0 & & \\
\hline $3 E$ & 30 & 2.07 & .87 & 1 & .70 & \\
\hline $3 F$ & 22 & 1.77 & .67 & 10 & 1.30 & .56 \\
\hline $4 \mathrm{E}$ & 31 & 1.59 & .62 & 1 & 1.14 & . \\
\hline $4 \mathrm{~F}$ & 29 & 1.66 & .72 & 2 & 1.57 & .31 \\
\hline $4 \mathrm{G}$ & 18 & 1.49 & .47 & 14 & 1.23 & .49 \\
\hline $5 B$ & 31 & 1.28 & .49 & 1 & 3.42 & \\
\hline $5 C$ & 28 & 2.03 & .87 & 2 & 2.15 & .36 \\
\hline $6 \mathrm{~B}$ & 30 & 1.51 & .63 & 2 & 3.06 & .65 \\
\hline $6 \mathrm{C}$ & 24 & 1.24 & .41 & 8 & 1.19 & .26 \\
\hline $7 \mathrm{~B}$ & 31 & 1.00 & .36 & 1 & .66 & \\
\hline $7 \mathrm{C}$ & 32 & 1.03 & .34 & 0 & & \\
\hline $8 B$ & 32 & 1.19 & .64 & 0 & & \\
\hline $8 C$ & 0 & .90 & .28 & 0 & & \\
\hline $9 \mathrm{~B}$ & 32 & .95 & .21 & 0 & & \\
\hline $9 \mathrm{C}$ & 32 & .98 & .43 & 0 & & \\
\hline $10 \mathrm{~B}$ & 32 & .91 & .20 & 0 & & \\
\hline $10 \mathrm{C}$ & 31 & .81 & .22 & 1 & .69 & \\
\hline
\end{tabular}

overall performance level did not support the assumption that the detection of a part would be an easy task for subjects if the pattern were physically present. In order to determine whether the high error rate was the result of the fast response times, Experiment II eliminated the need to respond rapidly by giving subjects $10 \mathrm{sec}$ to make their decision. Experiment II also provided for a more direct comparison between the perception and imagery tasks by including both tasks in the experimental design.

\section{EXPERIMENT II}

\section{Methods}

Subjects and Procedure. Eighty subjects participated in Experiment II. All were enrolied in introductory psychology courses at Case Western Reserve University. They reœived course credit for their participation.

The design consisted of two groups, with 40 subjects in each group. The imagery group was shown the complete pattern first and instructed to indicate whether the second pattern was a part of the first pattern. The perception group was shown the complete pattern second and was instructed to indicate whether the first pattern was a part of the second pattern. There were four presentation orders used in the experiment with the presentation orders being the same for both groups, except for the reversal of patterns within a pair. The experiment alternated between the image $y$ condition and the perception condition after every 10 subjects.

The first pattem was presented for $2 \mathrm{sec}$, and the second pattern was presented for $10 \mathrm{sec}$ after a 1 -sec delay between patterns. Subjects were instructed to respond when they heard a tone which occurred at the end of the 10-sec interval. They 
responded positively by pushing a switch held in their right hand and negatively by pushing a switch held in their left hand. The intertrial interval was $7 \mathrm{sec}$. The equipment was the same as used in Experiment I.

The imagery condition was similar to Reed's (1974) Experiment II except that the previous experiment used a 1-sec presentation interval for the first pattern and a 5 -sec presentation interval for the second pattern. The longer presentation intervals used in the present experiment were included to give subjects additional time to possibly improve their performance. In addition, an attempt was made in the present experiment to determine the extent to which subjects' positive responses in the imagery condition were the result of having seen the part when the complete pattern was presented. The instructions indicated that following a positive response, subjects should respond with the word "perception" if they had previously seen the part and with "memory" if they had not seen the part. A final difference was that there was a change in the stimuli resulting from the addition of two positive pairs and the deletion of three negative pairs. The positive pairs were $1 \mathrm{~B}$, 1C, 1D, 1E, 2A, 2C 2D, 2E, 3A, 4A, 4B, and 5A. The negative pairs were $1 \mathrm{~F}, 1 \mathrm{I}, 2 \mathrm{~F}, 2 \mathrm{G}, 3 \mathrm{E}, 3 \mathrm{~F}, 5 \mathrm{C}$, and $6 \mathrm{~B}$.

\section{Results}

Table 3 shows the number of errors for the perception and imagery conditions. Performance substantially improved on the perception task when subjects were given $10 \mathrm{sec}$ to make their decision. The average error probability for the 13 positive pairs shown in Table 3 was 0.48 in Experiment $\mathrm{I}$ and 0.14 in Experiment II. The large decline in errors shows that the fast RTs found in Experiment I were achieved only at a cost of a very high error probability. The paradigm used in Experiment II therefore appears to be a better procedure for measuring the subject's ability to perform in an embedded figures detection task.

The main comparison, however, is between the two conditions of Experiment II. In contrast to the 0.14 error probability in the perception condition, there was an error probability of 0.48 in the imagery condition. Subjects performed significantly worse on 10 of the 13 pairs when they had to scan an image rather than a perceptual pattern. These comparisons were based on a priori orthogonal tests using an $\propto$ level of $.05 / 21$ since there were 21 comparisons (Kirk, 1968, pp. 73-78). Two of the pairs (1D and 3C) were easy enough for subjects to do well in the imagery condition, and one pair (5A) was so difficult that subjects did as poorly in the perception condition as they did in the imagery condition. The subjects in the imagery condition also did better in responding to the negative pairs, although the difference was significant for only one pair (3E).

Although the error probability in the perception task was higher than we expected, it was substantially less than in the imagery task. This is particularly true if a correction is made for those cases in which the subjects responded correctly in the imagery task because they saw the part when the comparison pattern was presented. Table 3 shows the verbal reports for each of the 13 positive pairs. Of the 272 correct responses given to the positive pairs in the imagery task, 94 were based on previous preception of the part, according to the subjects' verbal reports. If these responses are eliminated from the analysis, the error probability for the positive pairs in the imagery task increases from 0.48 to 0.72 .

The validity of the verbal report, of course, depends on the extent to which subjects can correctly judge the basis for their decision. One converging operation which is related to the validity of the verbal report concerns incorrect positive responses to negative pairs. Since the part was not actually present in these cases, few of the verbal reports should indicate previous perception of the part. The data in Table 3 support this hypothesis since none of the 32 positive responses to the negative pairs were based on prior perception, according to subjects' verbal reports.

These results support Reed's (1974) previous data which show that subjects are limited in their ability to detect a part of a visual image. In order to demonstrate that this failure is due to the structural encoding of patterns and the limited accuracy of visual images rather than to the lack of memory for the complete pattern, it is necessary to show that subjects can remember the complete pattern. Reed (1974) presented several arguments that the poor performance was not the result of failure to remember the complete pattern: (1) subjects could almost always recognize the complete pattern, (2) the patterns were usually presented a number of times during the experiment, and (3) performance was particularly poor for many parts of the

Table 3

Comparison of Perception and Imagery Tasks

\begin{tabular}{|c|c|c|c|c|}
\hline & \multicolumn{2}{|c|}{ Errors } & \multicolumn{2}{|c|}{ Verbal Report } \\
\hline & Perception & Imagery & Perception & Memory \\
\hline \multicolumn{5}{|c|}{ Positive Pairs } \\
\hline 1B & 0 & $13^{*}$ & 13 & 14 \\
\hline $1 \mathrm{C}$ & 2 & $14^{*}$ & 12 & 14 \\
\hline $1 \mathrm{D}$ & 0 & 5 & 20 & 15 \\
\hline $1 \mathrm{E}$ & 0 & $27^{*}$ & 2 & 11 \\
\hline $2 \mathrm{~A}$ & 2 & $14^{*}$ & 6 & 20 \\
\hline $2 \mathrm{C}$ & 15 & $30 *$ & 0 & 10 \\
\hline $2 \mathrm{D}$ & 4 & $23 *$ & 2 & 15 \\
\hline $2 \mathrm{E}$ & 1 & $22 *$ & 6 & 12 \\
\hline $3 \mathrm{~A}$ & 3 & $17^{*}$ & 6 & 17 \\
\hline $3 \mathrm{C}$ & 0 & 4 & 23 & 13 \\
\hline $4 \mathrm{~A}$ & 17 & $32^{*}$ & 0 & 8 \\
\hline $4 B$ & 1 & $17^{*}$ & 3 & 20 \\
\hline $5 \mathrm{~A}$ & 28 & 30 & 1 & 9 \\
\hline \multicolumn{5}{|c|}{ Negative Pairs } \\
\hline $1 \mathrm{~F}$ & 0 & 2 & 0 & 2 \\
\hline 11 & 2 & 3 & 0 & 3 \\
\hline $2 F$ & 5 & 6 & 0 & 6 \\
\hline $2 \mathrm{G}$ & 0 & 1 & 0 & 1 \\
\hline $3 \mathrm{E}$ & 2 & $15^{*}$ & 0 & 15 \\
\hline $3 \mathrm{~F}$ & 3 & 3 & 0 & 3 \\
\hline $5 \mathrm{C}$ & 1 & 2 & 0 & 2 \\
\hline $6 B$ & 2 & 0 & 0 & 0 \\
\hline
\end{tabular}

${ }^{*} p<.05 / 21$ based on a priori orthogonal comparisons. 
Star of David even though it is a familiar pattern. The purpose of Experiment III was to provide a more direct test of this assertion by requiring subjects to draw Patterns I and II after making a series of decisions regarding their parts.

\section{EXPERIMENT III}

\section{Method}

Subjects and Procedure. Experiment III was conducted as a class experiment. The subjects were enrolled in a cognitive psychology course. Although 41 subjects participated in the experiment, two subjects had been in one of the previous versions of the experiment and were not included in the analysis.

The subjects were informed that the purpose of the experiment was to investigate the accuracy of visual images. They were initially instructed that they would be shown a pattern for $5 \mathrm{sec}$ and then would be asked various questions about it. After being shown Pattern 1 for $5 \mathrm{sec}$, they were informed that they would see a series of possible parts of Patterm $\mathrm{I}$ and that they should indicate whether each pattern was a part. The series consisted of Patterns 1B, 1C, 1H, 1D, 1F, and 1E. Each pattern in the series was shown for $10 \mathrm{sec}$, and subjects were asked to respond at the end of the $10-\sec$ interval. There was approximately $5 \mathrm{sec}$ between slides. At the end of the series, subjects were asked to draw Pattern I.

The subjects were then shown Pattern II for $5 \mathrm{sec}$, followed by 10-sec presentations of Patterns 2I, 2A, 2B, 2G, 2C, 2D, 2F, and $2 \mathrm{E}$. They were again instructed to indicate at the end of each exposure whether that pattern was a part of Pattem 2. At the end of the series, they were again asked to draw Pattern 2. All patterns were projected onto a screen in front of the classroom.

\section{Results}

The primary purpose of Experiment III was to investigate the accuracy of the subjects' memory for the complete pattern through their drawings of Pattern 1 and Pattern 2 at the end of each series. Independent evaluations of the drawings by the two experimenters resulted in complete agreement: All subjects correctly drew Pattern 1 and all but one subject correctly drew Pattem 2. The results support the hypothesis that limitations in detecting a part of a pattern are not the result of the subjects' inability to remember the complete pattern.

The number of errors on the positive patterns were 10 for Pattern 1B, 13 for 1C, 3 for 1D, 24 for $1 E, 22$ for $2 \mathrm{~A}, 2$ for $2 \mathrm{~B}, 17$ for $2 \mathrm{C}, 17$ for $2 \mathrm{D}$, and 8 for $2 \mathrm{E}$. The number of errors on the negative patterns were 3 for Pattern 1H, 3 for $1 F, 2$ for $2 \mathrm{I}, 5$ for $2 \mathrm{G}$, and 5 for $2 \mathrm{~F}$. A comparison of these results with the results of Experiment II reveals a fairly comparable performance for Pattern I, but a better performance in Experiment III for Pattern 2. This is most likely the result of the longer $(5 \mathrm{sec})$ exposure of Pattern 2 in this experiment, which may have encouraged subjects to scan Pattern 2 for various parts. Since the task was not identified as an embedded figures task until after Pattern 1 had been presented, it is unlikely that subjects looked for various parts in Pattern 1. The longer exposure duration was selected because subjects saw the complete pattern only once in Experiment III, in contrast to the previous experiment which presented the complete pattern on each trial. Unfortunately, the "perception-memory" verbal report procedure was not used since we thought it desirable to keep the instructions as short as possible.

\section{DISCUSSION}

Recent formulations of information processing models have emphasized the importance of both visual and verbal memory codes for storing information about visual patterns (see Reed, 1973, pp. 111-137, for specific examples). In order to examine the accuracy of visual images, it is therefore necessary to design research paradigms in which the verbal code can have only a minimum influence on subjects' performance. An excellent example is a paradigm which uses infants as subjects. Although visual memory of infants is quite good (Fagan, 1973) it is less clear how visual memory changes with age following the acquisition of language.

The present paradigm attempted to minimize the role of language by asking subjects to scan a visual image to detect a part of a pattern. A RT paradigm was initially used (Reed, 1974) in an attempt to determine which decisions were based on previous perception of the part as opposed to the scanning of a visual image. However, the RT data are of limited value for two reasons. First, although RTs based on prior perception should be faster than RTs based on scanning an image, it is not obvious how the decision should be made. Second, the data from Experiment I indicate that subjects make many errors in a RT paradigm even when they scan a pattern which is physically present in a perception task.

The data from Experiment II showed that the high error rate in the perception task declined substantially when subjects were allowed $10 \mathrm{sec}$ to make their decision. The $14 \%$ error rate found in the perception task in Experiment II was substantially less than the $48 \%$ error rate found in the imagery task and the $72 \%$ error rate estimated for the imagery task when corrections were made for previous perception of a part. The data from the perception task provided a useful methodological control for several reasons. First, the overall error rate provides a base line against which to compare performance in the imagery task. Second, the findings indicate that some patterns (such as 6A) are extremely difficult to detect even when the entire pattern is physically present. Such extremely difficult parts should therefore be excluded from future use of the imagery paradign since they violate the assumption that the task should not be difficult when the complete pattern is physically present.

The results on the perception task were generally 
consistent with the results obtained by Gottschaldt (1926). Gottschaldt found that subjects usually did not detect a part which failed to correspond with their initial perceptual organization unless they were given sufficient time to search for it. The RTs in Experiment I were generally less than $2 \mathrm{sec}$, which suggests that the subject often responded on the basis of his initial perceptual organization without searching for the part. One interesting question is what factors influence the subject's initial organization of a pattern. Gottschaldt's work demonstrated that various figural factors which produced "internal unity" of the complete pattern were very influential in determining the difficulty of finding an embedded figure, whereas the frequency of seeing the isolated parts had little influence.

Experiment III examined the assumption that the difficulty of the imagery task is not the result of the subjects' inability to remember the complete pattern. The results of Experiment III, in which subjects accurately drew Patterns 1 and 2, lend support to this assumption. The limitation, therefore, seems to be more the result of the subjects' inability to maintain or generate an accurate visual image rather than the result of their inability to encode the pattern, as found by Rock, Halper, and Clayton (1972) when using patterns of greater complexity. The subjects apparently form structural descriptions of the patterns shown in Figure 1 which are adequate enough to describe the pattern completely, but are at least partially dependent on verbal concepts. They can use verbal concepts such as "diamond," "bisect," and "join" to draw the pattern, but are more dependent on visual imagery when asked a question about a previously unseen part, since the name of that part could not have been activated. When asked a question that requires examination of a visual image (detecting an unseen part), their performance is far below their performance when verbal concepts can be used (drawing the pattern).

This interpretation of the results emphasizes the limited accuracy of visual images as an explanation of subjects' poor performance in the imagery task. However, an alternative explanation based on task interference cannot be ruled out by the data presented here. ${ }^{1}$ The alternative interpretation proposes that visual images are accurate representations of the stimulus, but are easily interfered with when subjects perform some operation on them such as scanning the image for a part or trying to reorganize a structured image. When subjects are asked a question regarding a previously unseen part, they have to maintain a visual image in memory and simultaneously perform some operation upon the image.

Perfomance may be limited either because the separate demands of the task interfere with each other as a result of their structural similarity or because they exceed the limited capacity of the subjects' working memory (see Kahneman, 1973, for a discussion of the distinction between "structural" and "capacity" theories of attention). One way in which the separate aspects of the imagery task could interfere with each other is that the second pattern remains on the screen until the subject responds. Looking at the part may interfere with the subject's ability to scan a visual image in the same way that pointing to responses in a visual array interfered with the subjects' ability to scan a visual image of a block letter in Brooks' (1968) experiment.

Emphasizing the operational nature of the task would also be consistent with Piaget and Inhelder's (1969) distinction between static and transformational images. Piaget and Inhelder argue that static images (such as recognizing a picture) occur quite early developmentally, but transformational images (such as visualizing the bending of a rod) develop only after the child reaches the stage of concrete operations. The greater complexity of transformational images might explain why subjects performed poorly in the present task, but usually perform very well when they are asked to recognize pictures in a recognition memory task (Standing, 1973). Thus further research is necessary to determine whether the poor performance found here was the result of the limited accuracy of images when subjects could not utilize verbal concepts or the result of mental operations which interfered with highly accurate images.

It is hoped that these results will contribute a small amount to the challenge raised by Pylyshyn (1973). Pylyshyn argued that, although the usefulness of imagery cannot be questioned, images should $\overline{\text { not ve }}$ treated as primitive explanatory constructs, not requiring further reduction in psychological theories of cognition. His argument that images are closer to being a description than a picture is supported by the present data. Although these findings suggest that images are highly schematic, the results are not specific enough to form the basis for the kind of detailed models advocated by Pylyshyn to indicate what operations subjects use in an imagery task. Previous analysis of these patterns (Reed \& Angaran, 1972; Reed, 1973, pp.4749), which placed a greater emphasis on their structural characteristics, might form the basis for specifying such operations but more detailed models will require more detailed data than is currently available.

\section{REFERENCES}

Brooks, L. R. Spatial and verbal components of the act of recall. Canadian Joumal of Psychology, 1968, 22, 349-368.

Fagan, J, F. Infant's delayed recognition memory and forgetting. Joumal of Experimental Child Psychology, 1973, 16, 424-450.

Gottschaldt, K. Ueber den Einfluss gehaufter Einpragung auf die Wahrnehmung von Figuren: I. Ueber den Einfluss gehaufter Einpragung von Figuren auf ihre Sichbarkeit in umfassenden Konfigurationen. Psychologishe Forschung, 1926,8, 261-318. (or see translation, Gestalt factors in repetition. In W. D. Ellis (Ed.), A source book of Gestalt psychology. New York: Humanities Press, 1938, pp. 109-135.

Kahneman, D. Attention and effort. New Jersey: Englewood Cliffs: Prentice-Hall, 1973. 
Kirk, R. E. Experimental design: Procedures for the behavioral sciences. Belmont, Ca.: Brooks/Cole, 1968.

Piaget, J. \& Inhelder, B. Mental images. In P. Fraisse \& J. Piaget (Eds.), Experimental psychology: VII. Intelligence. London: Routledge \& Kegan Paul, 1969.

Pylyshyn, $Z$. W. What the mind's eye tells the mind's brain: A critique of mental imagery. Psychological Bulletin, 1973, 80 . 1-24.

Reed, S. K. Psychological processes in pattern recognition. New York: Academic Press, 1973.

Reed, S, K. Structural descriptions and the limitations of visual images. Memory \& Cognition, 1974, 2, 329-336.

Reed, S. K. \& Angaran, A. J. Structural models and embedded figure difficulty for normal and retarded children. Perceptual and Motor Skills, 1972, 35, 155-164.

Rock, I. Halper, F. \& Clayton, T. The perception and recognition of complex figures. Cognitive Psychology, 1972, $3,655-673$.
Standing, L. Learning 10,000 pictures. Quarterly Journal of Experimental Psychology, 1973, 25, 207-222.

Sutherland, N. S. Outlines of a theory of visual pattern recognition in animals and man. Proceedings of the Royal Society, 1968, 171, 297-317.

\section{NOTE}

1. This explanation was suggested by Dr. Michael Posner and an anonymous reviewer as a possible alternative explanation of the results.

(Received for publication September 7, 1974: revision received November $5,1974$. 